\title{
Chlorine 36 fallout in the Summit Greenland Ice Core Project ice core
}

\author{
S. Baumgartner, ${ }^{1}$ J. Beer, ${ }^{1}$ M. Suter, ${ }^{2}$ B. Dittrich-Hannen, ${ }^{2}$ H.-A. Synal, ${ }^{3}$ \\ P. W. Kubik, ${ }^{3}$ C. Hammer, ${ }^{4}$ and S. Johnsen ${ }^{4,5}$
}

\begin{abstract}
The natural cosmogenic radioisotope ${ }^{36} \mathrm{Cl}$ has been measured in the Greenland Ice Core Project ice core from Summit, Greenland. Generally, a good correlation between ${ }^{36} \mathrm{Cl}$ and $\delta^{18} \mathrm{O}$ was found, even in glacial periods with strong $\delta^{18} \mathrm{O}$ oscillations. The ${ }^{36} \mathrm{Cl}$ flux is calculated assuming an exponential relationship between accumulation rate and $\delta^{18} \mathrm{O}$. A prominent excursion is detected between 35 and $40 \mathrm{kyr}$ B.P., which coincides with a similar ${ }^{10} \mathrm{Be}$ peak measured in the same samples. This sheds light on possible causes of this excursion. In the lowest part of the ice core the flux decreases smoothly. This can be interpreted as radioactive decay of ${ }^{36} \mathrm{Cl}\left(T_{1 / 2}=300 \mathrm{kyr}\right)$.
\end{abstract}

In 1992 the joint European Greenland Ice Core Project (GRIP) finished its deep drilling at Summit, Greenland [Dansgaard et al., 1993]. A large number of interesting data sets have already been published, for example $\delta^{18} \mathrm{O}$ [Dansgaard et al., 1993], electrical conductivity [Taylor et al., 1993], Ca, HCHO, $\mathrm{NH}_{4}$ [Fuhrer et al., 1993], and $\mathrm{CH}_{4}$ [Chappellaz et al., 1993; Blunier et al., 1995]. We present here for the first time measurements of the cosmogenic radionuclide ${ }^{36} \mathrm{Cl}$ from the deeper part of the Greenland Ice Sheet. These ${ }^{36} \mathrm{Cl}$ data complement the ${ }^{10} \mathrm{Be}$ data [Yiou et al., this issue] in the same core.

With a few exceptions [Finkel et al., 1980; Conard et al., 1989; Elmore et al., 1987; Suter et al., 1987], studies using natural atmospheric ${ }^{36} \mathrm{Cl}$ in the Earth sciences have so far been restricted to hydrological and geological studies [e.g., Bentley et $a l ., 1986]$. Recent progress at the accelerator mass spectrometry (AMS) facility at Zurich, however, made it possible to measure up to 50 samples per day [Synal et al., 1994]. It is now possible to produce the large data sets which are needed for paleoclimatic studies such as the GRIP project.

Natural cosmogenic ${ }^{36} \mathrm{Cl}$ is produced in the atmosphere mainly by neutron- and proton-induced spallation reactions on ${ }^{40} \mathrm{Ar}$ [Bentley et al., 1986]. The neutrons and protons originate from the charged cosmic ray particle nuclear cascade. The production rate of ${ }^{36} \mathrm{Cl}$ is proportional to the cosmic ray flux, which is modulated by the Earth's magnetic field and the magnetic properties of the solar wind [Lal and Peters, 1967]. Within about 2 years, ${ }^{36} \mathrm{Cl}$ is removed from the atmosphere and stored in terrestrial deposits, e.g., ice sheets [Synal et al., 1990].

Except for the Holocene/Wisconsin transition period, the GRIP ice core has been sampled continuously for the measurement of the cosmogenic radioisotopes ${ }^{10} \mathrm{Be},{ }^{36} \mathrm{Cl}$, and ${ }^{26} \mathrm{Al}$. Each ${ }^{36} \mathrm{Cl}$ sample represents a $1.1-\mathrm{m}$-long section of the ice

\footnotetext{
${ }^{1}$ Environmental Physics, Swiss Federal Institute for Environmental Science and Technology, Dübendorf, Switzerland.

${ }^{2}$ Institute for Particle Physics, Eidgenössische Technische Hochschule Hönggerberg, Zurich, Switzerland.

${ }^{3}$ Paul Scherrer Institute, Villigen, Switzerland.

${ }^{4}$ Department of Geophysics, University of Copenhagen, Copenhagen, Denmark.

${ }^{5}$ Also at Science Institute, University of Iceland, Reykjavik.

Copyright 1997 by the American Geophysical Union.

Paper number 97JC00166.

0148-0227/97/97JC-00166\$09.00
}

core equivalent to two ${ }^{10} \mathrm{Be}$ samples [Yiou et al., this issue]. This sample length corresponds to about 6 years in the Holocene, at the top of the core, and to about 100 years in the Wisconsin at 2500-m depth. The time resolution at the bottom of the core is unknown. After adding $4 \mathrm{mg}$ of stable chlorine as carrier to the sample, ${ }^{36} \mathrm{Cl}$ and the carrier are extracted together by means of anion exchange resin. The eluted chlorine is treated with barium nitrate to remove ${ }^{36} \mathrm{~S}$, which has to be minimized for AMS analysis. Following standardized procedures [Lukasczyk, 1994], $\mathrm{AgCl}$ is formed and pressed on tantalum disks. The samples are analyzed using AMS at the Eidgenössische Technische Hochschule (ETH)/Paul Scherrer Institute (PSI) AMS facility in Zurich [Synal et al., 1994].

We present the results of about 600 measurements of ${ }^{36} \mathrm{Cl}$ samples, covering parts of the Holocene and Pleistocene periods of the GRIP core. The measured ${ }^{36} \mathrm{Cl} / \mathrm{Cl}$ ratios range from $11 \times 10^{-15}$ to $240 \times 10^{-15}$ with a median isotopic ratio of $73 \times$ $10^{-15}$. This corresponds to ${ }^{36} \mathrm{Cl}$ concentrations between 700 and 14,000 atoms $\mathrm{g}^{-1}$. The overall average concentration in the ice is 4300 atoms $\mathrm{g}^{-1}$. Background measurements were always performed for every 20 samples. Reagent $\mathrm{AgCl}$ (Merck) and chemically treated carrier solution were taken as blank materials. The measured isotopic ratios are at the level of $1 \times$ $10^{-15}$, at least 10 times lower than the ${ }^{36} \mathrm{Cl} / \mathrm{Cl}$ ratios of the ice-core samples. The absolute ${ }^{36} \mathrm{Cl} / \mathrm{Cl}$ ratios are derived using the ETH/PSI internal standard material K380/4 which had been calibrated to a University of California, San Diego (UCSD), standard material (NBS SRM4422L) [Sharma et al., 1990]. Measurement uncertainties are calculated using the 1 sigma error introduced from the counting statistics and uncertainties from normalization and background correction. The overall uncertainties of the ${ }^{36} \mathrm{Cl}$ measurements range from 2 to $15 \%$; the median uncertainty of all measurements is close to $7 \%$. During sample preparation, cross contamination cannot be ruled out completely. Since isotopic ratios of adjacent samples are of the same order of magnitude and material transfer from sample to sample is minimized by careful sample preparation, the resulting errors are estimated not to exceed $1 \%$. No corrections have been made for natural chlorine in the samples. Since the chloride concentration is on the average smaller than $40 \mathrm{ppb}$ and peak values are lower than $200 \mathrm{ppb}(\mathrm{M}$. Legrand, personal communication, 1996), the corresponding underestimation of stable chlorine in the sample is on the 


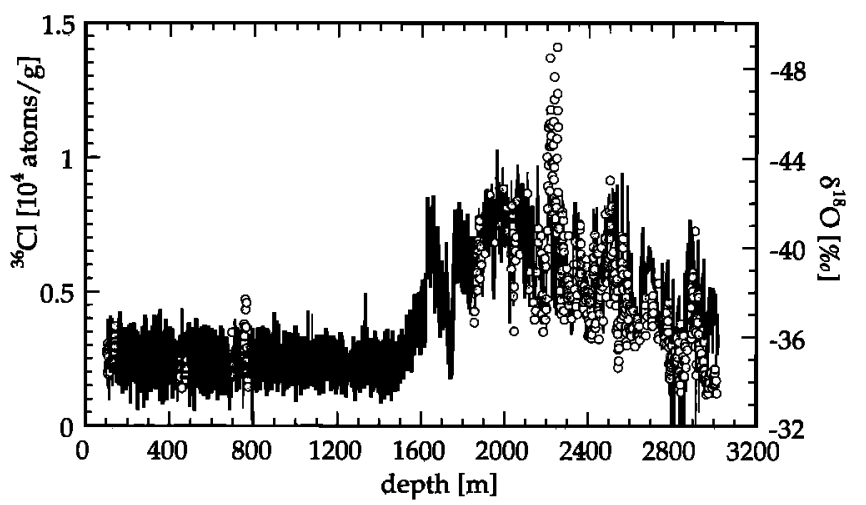

Figure 1. Chlorine $36\left(10^{4}\right.$ atoms per gram of ice; circles) and $\delta^{18} \mathrm{O}$ (per mil; solid trace) [Dansgaard et al., 1993] versus depth of the GRIP ice core from Summit, Greenland.

average smaller than $1 \%$ and smaller than $5 \%$ for seldom peak values. Thus we consider the error introduced by natural chlorine to be negligible compared to the AMS measurement uncertainties.

The concentration of ${ }^{36} \mathrm{Cl}$ in the ice depends on the cosmogenic ${ }^{36} \mathrm{Cl}$ production rate, on the atmospheric transport mechanisms, and on the removal processes of ${ }^{36} \mathrm{Cl}$ from atmosphere to ice. All these processes introduce fluctuations on different timescales. Rapid variations of the ${ }^{36} \mathrm{Cl}$ concentration in the ice can be due to solar modulation of the cosmic ray flux and to short-term climatic changes in accumulation rate or global atmospheric mixing. On a longer timescale, however, long-term climatic effects and geomagnetic shielding will drive the general trend in the data.

First, we compare the measured ${ }^{36} \mathrm{Cl}$ concentrations in the ice with the corresponding $\delta^{18} \mathrm{O}$ values [Dansgaard et al., 1993] (Figure 1). Except for a prominent excursion between 2200and $2250-\mathrm{m}$ depth and the decrease at the bottom of the core, a good correlation can be observed: high $\delta^{18} \mathrm{O}$ values correspond to low ${ }^{36} \mathrm{Cl}$ concentrations and vice versa. This is true throughout all the examined parts of the Wisconsin with its rapidly changing $\delta^{18} \mathrm{O}$ (Figure 2 ). In this part of the core the ${ }^{36} \mathrm{Cl}$ concentration varies between 4000 and 8000 atoms (g ice) ${ }^{-1}$ (with the exception of the excursion).

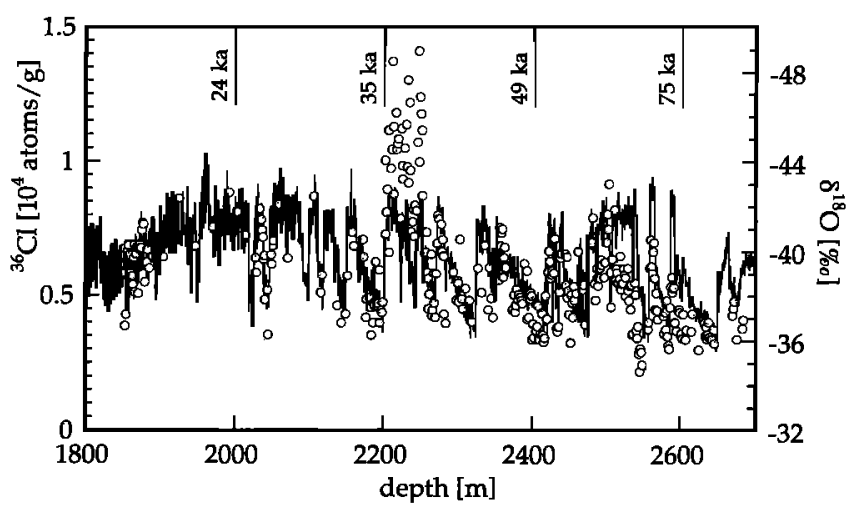

Figure 2. Chlorine $36\left(10^{4}\right.$ atoms per gram of ice; circles) and $\delta^{18} \mathrm{O}$ (per mil; solid trace) [Dansgaard et al., 1993] versus depth in the Wisconsin part of the GRIP ice core from Summit, Greenland. The indicated ages (kiloyears B. P.) correspond to the provisional GRIP timescale [Dansgaard et al., 1993].
Such a correlation between cosmogenic radionuclides and $\delta^{18} \mathrm{O}$ in ice cores was already discovered for ${ }^{10} \mathrm{Be}$ [Raisbeck et al., 1992; Beer et al., 1992]. The most probable mechanism for this correlation is a dilution effect: a higher precipitation rate during warmer periods (higher $\delta^{18} \mathrm{O}$ ) leads to a reduced ${ }^{36} \mathrm{Cl}$ concentration in the ice. Such a mechanism does not imply that the dominant atmospheric removal process is dry fallout; it only requires the ${ }^{36} \mathrm{Cl}$ flux to be accumulation independent.

The paleoaccumulation rate $\lambda$ (meters per year) at Summit was determined by annual layer counting to be exponentially dependent on $\delta^{18} \mathrm{O}$ [Dansgaard et al., 1993]:

$$
\lambda=0.23 \frac{m}{a} e^{\left[0.144\left(8^{18} \mathrm{O}+348\right)\right]}
$$

If the interpretation of the ${ }^{36} \mathrm{Cl} / \delta^{18} \mathrm{O}$ correlation as dilution effect is correct, we also expect an exponential dependence of ${ }^{36} \mathrm{Cl}$ on $\delta^{18} \mathrm{O}$ with the same slope. This is indeed the case (compare Figure 3). Climatically independent factors which change the ${ }^{36} \mathrm{Cl}$ flux, such as radioactive decay in the bottom part of the core or the mentioned excursion in ${ }^{36} \mathrm{Cl}$ deposition, disturb the correlation. Therefore data between 2200 and $2250 \mathrm{~m}$ as well as below $2900 \mathrm{~m}$ are not used in the calculation of the $\delta^{18} \mathrm{O} /{ }^{36} \mathrm{Cl}$ correlation. The slope obtained in this way is $0.134 \pm 0.005$. This has to be compared with the value of $0.144 \pm 0.006$ obtained independently by annual layer counting. The good agreement supports the interpretation of the rapidly fluctuating $\delta^{18} \mathrm{O}$ in the Wisconsin as real, at least hemispheric temperature effect with corresponding consequences for the precipitation rate, as also indicated by methane [Chappelaz et al., 1993], sea surface temperature [Bond et al., 1993], and pollen [Grimm et al., 1993] measurements.

A changing source region for ${ }^{36} \mathrm{Cl}$ is another possibility to explain the observed $\delta^{18} \mathrm{O} /{ }^{36} \mathrm{Cl}$ correlation. Alterations in atmospheric structure and circulation could change the source of ${ }^{36} \mathrm{Cl}$ in its spatial distribution, which could lead to incorporation of areas with higher or lower radionuclide production. An important shift of the global moisture paths to Greenland does not seem to be expected [Charles et al., 1994; Johnsen et al., 1989] but cannot be ruled out for sure. A changing height of the tropopause as a function of climate might also influence the ${ }^{36} \mathrm{Cl}$ flux over Greenland [Lal, 1987]. It is difficult to judge whether such scenarios are realistic or not. However, we con-

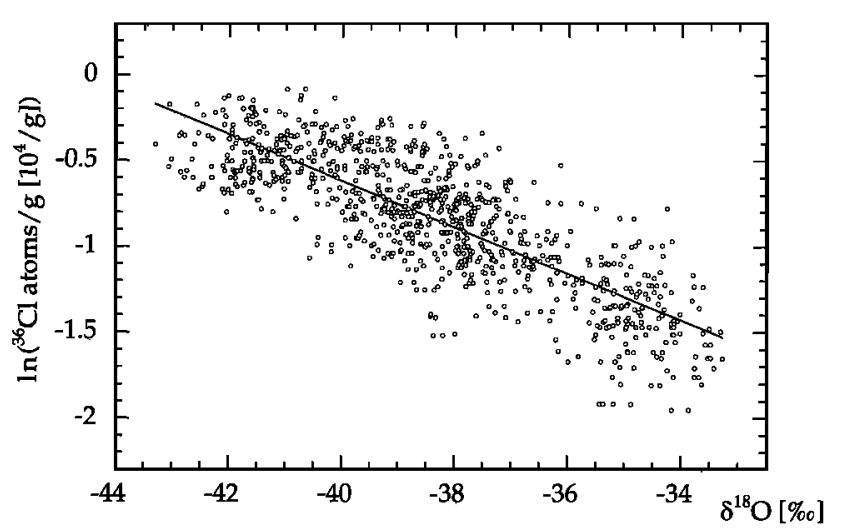

Figure 3. Logarithm of the ${ }^{36} \mathrm{Cl}$ concentration $\left(10^{4}\right.$ atoms per grams of ice) as a function of $\delta^{18} \mathrm{O}$ (per mil) [Dansgaard et al., 1993]. The data of the prominent excursion between 2200and $2250-\mathrm{m}$ depth and from the bottom of the core are excluded in this plot and in the linear regression $(r=0.8)$. 
clude from the similarity of the $\delta^{18} \mathrm{O} /{ }^{36} \mathrm{Cl}$ with the $\delta^{18} \mathrm{O} / \lambda$ correlation that the ${ }^{36} \mathrm{Cl}$ flux at Summit is basically independent of $\delta^{18} \mathrm{O}$. The general trend in the ${ }^{36} \mathrm{Cl}$ concentration data can therefore be described as a dilution effect caused by changes in the accumulation rate. This view allows to calculate the ${ }^{36} \mathrm{Cl}$ flux by multiplying the ${ }^{36} \mathrm{Cl}$ concentration with the ice density and the accumulation rate $\lambda$ as deduced from annual layer counting.

The average ${ }^{36} \mathrm{Cl}$ flux at Summit $\left(72^{\circ} \mathrm{N}\right)$ is $19 \pm 3$ atoms $\mathrm{m}^{-2}$ $\mathrm{s}^{-1}$, excluding the peak region. This value can be compared with $20 \pm 6$ atoms $\mathrm{m}^{-2} \mathrm{~s}^{-1}$ at Dye $3\left(65^{\circ} \mathrm{N}\right)$ [Synal et al., 1994], $24 \pm 7$ atoms $\mathrm{m}^{-2} \mathrm{~s}^{-1}$ at Milcent $\left(70^{\circ} \mathrm{N}\right)$ [Synal et al., 1994], and 24 atoms $\mathrm{m}^{2} \mathrm{~s}^{-1}$ at Camp Century $\left(77^{\circ} \mathrm{N}\right)$ [Conard et al., 1989]. Thus the ${ }^{36} \mathrm{Cl}$ flux does not show the expected latitudinal dependence over Greenland [Lal and Peters, 1967]. This fact might be explained by the special meteorological situation of Greenland. The island receives most of its precipitation from moisture evaporating from all latitudes of the North Atlantic [Charles et al., 1994; Johnsen et al., 1989], which implies air masses traveling from the south toward Greenland. It is probable that these air masses also transport ${ }^{36} \mathrm{Cl}$. In this scenario the ${ }^{36} \mathrm{Cl}$ flux over Greenland is dominated by some sort of longitudinal average value of the ${ }^{36} \mathrm{Cl}$ flux over the North Atlantic; the local component must be rather small [Lal and Peters, 1967].

The time-dependent ${ }^{36} \mathrm{Cl}$ flux is shown in Figure 4. A prominent ${ }^{36} \mathrm{Cl}$ flux peak can be detected relative to the average background value between 2200- and $2250-\mathrm{m}$ depth, which corresponds to about $37 \mathrm{kyr}$ B.P. according to the preliminary GRIP timescale [Dansgaard et al., 1993]. The observed ${ }^{36} \mathrm{Cl}$ peak is simultaneous with the ${ }^{10} \mathrm{Be}$ peak [Yiou et al., this issue]. The two flux curves are quite similar in their general long-term behavior. The ${ }^{10} \mathrm{Be} /{ }^{36} \mathrm{Cl}$ ratio is discussed elsewhere [Yiou et al., this issue].

A corresponding ${ }^{10} \mathrm{Be}$ peak was previously found in the Vostok [Raisbeck et al., 1987, 1992], Dome C [Raisbeck et al., 1987], and Byrd [Beer et al., 1992] ice cores from Antarctica. Some evidence has also been found in the Camp Century ice core [Beer et al., 1992] from Greenland. There are also hints of similar ${ }^{10} \mathrm{Be}$ excursions in sediment cores from the Mediterranean Sea [Castagnoli et al., 1995] and from the Gulf of California [McHargue et al., 1995].

Explanations for the peak could be a change in the production rate by a lower geomagnetic field of the Earth, low solar activity, or an increase in the primary cosmic radiation. Another possibility would be an increase in the cosmic dust load. The fact that the peak is observed in both ${ }^{36} \mathrm{Cl}$ and ${ }^{10} \mathrm{Be}$ strengthens the interpretation as a production effect [Yiou et $a l$., this issue]. This also implies that the origin of this peak cannot be due to increased terrestrial dust transport, since ${ }^{36} \mathrm{Cl}$ is much less bound to dust than ${ }^{10} \mathrm{Be}$.

All information available so far clearly indicates that the ${ }^{10} \mathrm{Be}$ and the ${ }^{36} \mathrm{Cl}$ peak can be viewed as a global time marker. It can therefore be used for interhemispheric synchronization of paleoclimatic time series [Yiou et al., this issue].

The ${ }^{10} \mathrm{Be}$ peak identified at about $60 \mathrm{ka}$ in the Vostok ice core [Raisbeck et al., 1987] could not be found in the Summit core with the same strength. Some possible explanations for this discrepancy are discussed by Yiou et al. [this issue] in their ${ }^{10} \mathrm{Be}$ paper.

Except for the peak region and the bottom part of the core, the ${ }^{36} \mathrm{Cl}$ flux curve looks rather flat on a longer timescale. Only between 2500 - and $2800-\mathrm{m}$ depth does the ${ }^{36} \mathrm{Cl}$ flux seem to be

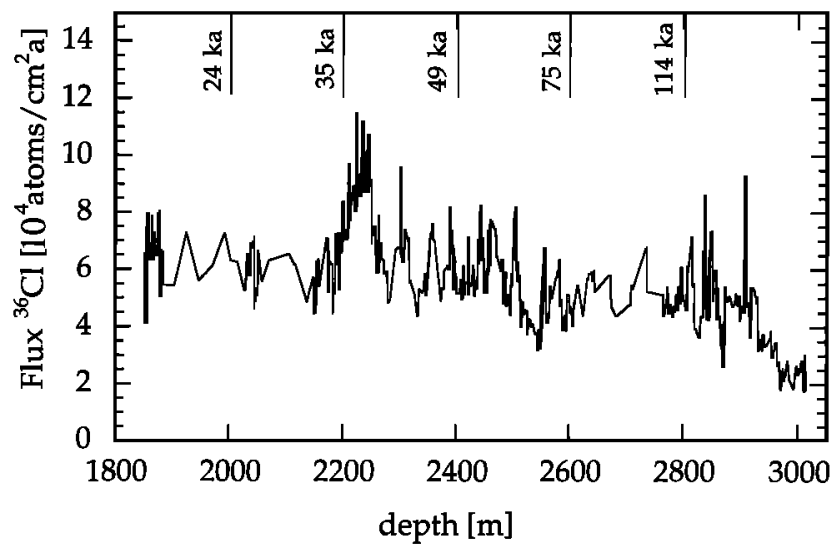

Figure 4. Chlorine 36 flux $\left(10^{4}\right.$ atoms per square centimeter per year) in the lower part of the ice core. The indicated ages (kiloyears B. P.) correspond to the provisional GRIP timescale [Dansgaard et al., 1993].

somewhat reduced. Whether this is due to geomagnetic modulation or to a time-dependent change in the accumulation rate cannot be decided yet. Superimposed on the long-term trend are short-term perturbations, which will be discussed in more detail elsewhere. At the bottom of the core the measured ${ }^{36} \mathrm{Cl}$ flux apparently decreases by a factor of 2 . A possible explanation of this rather smooth decrease of the ${ }^{36} \mathrm{Cl}$ flux is the radioactive decay of ${ }^{36} \mathrm{Cl}\left(T_{1 / 2}=300 \mathrm{kyr}\right)$. A detailed discussion of this phenomenon will be published elsewhere.

Acknowledgments. We wish to thank P. Ehrismann, C. Roth, Y Weidmann, and S. Bollhalder for their valuable lab work and the GRIP field team for drilling the ice core in its excellent quality. We also acknowledge the major support by the accelerator crew at the PSI/ETH AMS facility. This work was supported by the Swiss National Science Foundation. The ${ }^{36} \mathrm{Cl}$ data are available from the authors upon request (beer@eawag.ch or synal@particle.phys.ethz.ch).

\section{References}

Beer, J., S. J. Johnsen, G. Bonani, R. C. Finkel, C. C. Langway, H. Oeschger, B. Stauffer, M. Suter, and W. Wolfli, ${ }^{10} \mathrm{Be}$ peaks as time markers in polar ice cores, in The Last Deglaciation: Absolute and Radiocarbon Chronologies, edited by E. Bard and W. S. Broecker, pp. 141-153, Springer-Verlag, New York, 1992.

Bentley, H. W., F. M. Phillips, and S. N. Davis, Chlorine-36 in the terrestrial environment, in Handbook of Environmental Isotope Geochemistry, edited by P. Fritz and J. C. Fontes, pp. 427-480, Elsevier Sci., New York, 1986.

Blunier, T., J. Chapellaz, J. Schwander, B. Stauffer, and D. Raynaud, Variations in atmospheric methane concentration during the Holocene epoch, Nature, 374, 46-49, 1995.

Bond, G., W. Broecker, S. Johnsen, J. McManus, L. Labeyrie, J. Jouzel, and G. Bonani, Correlations between climate records from North Atlantic sediments and Greenland ice, Nature, 365, 143-147, 1993.

Castagnoli, G. C., et al., Evidence for enhanced ${ }^{10} \mathrm{Be}$ deposition in Mediterranean sediments 35 kyr BP, Geophys. Res. Lett., 22(6), $707-710,1995$.

Chappellaz, J., T. Blunier, D. Raynaud, J. M. Barnola, J. Schwander, and B. Stauffer, Synchronous changes in atmospheric $\mathrm{CH}_{4}$ and Greenland climate between 40 and 8 kyr BP, Nature, 366, 443-445, 1993.

Charles, C. D., D. Rind, J. Jouzel, R. D. Koster, and R. G. Fairbanks, Glacial-interglacial changes in moisture sources for Greenland: Influences on the ice core record of clımate, Science, 263, 508-511, 1994.

Conard, N. J., P. W. Kubik, H. E. Gove, and D. Elmore, $\mathrm{A}^{36} \mathrm{Cl}$ profile 
in Greenland ice from AD 1265 to 1865, Radiocarbon, 31(3), 585$591,1989$.

Dansgaard, W., et al., Evidence for general instability of past climate from a 250-kyr ice-core record, Nature, 364, 218-220, 1993.

Elmore, D., N. J. Conard, P. W. Kubik, H. E. Gove, M. Wahlen, J. Beer, and M. Suter, ${ }^{36} \mathrm{Cl}$ and ${ }^{10} \mathrm{Be}$ profiles in Greenland ice: Dating and production rate variations, Nucl. Instrum. Methods Phys. Res., Sect. B, 29, 207-210, 1987.

Finkel, R. C., K. Nishiizumi, D. Elmore, R. D. Ferraro, and H. E. Gove, ${ }^{36} \mathrm{Cl}$ in polar ice, rainwater and seawater, Geophys. Res. Lett., $7(11), 983-986,1980$.

Fuhrer, K., A. Neftel, M. Anklin, and V. Maggi, Continuous measurements of hydrogen peroxide, formaldehyde, calcium and ammonium concentrations along the new GRIP icecore from Summit, Central Greenland, Atmos. Environ., Part A, 27(12), 1873-1880, 1993.

Grimm, E. C., G. L. Jacobson, W. A. Watts, B. C. S. Hansen, and K. A. Maasch, A 50,000-year record of climate oscillations from Florida and its temporal correlation with the Heinrich events, Science, 261, 198-200, 1993.

Johnsen, S. J., W. Dansgaard, and J. W. C. White, The origin of Arctic precipitation under present and glacial conditions, Tellus, Ser. B, 41, 452-468, 1989.

Lal, D., ${ }^{10} \mathrm{Be}$ in polar ice: Data reflect changes in cosmic ray flux or polar meteorology, Geophys. Res. Lett., 14(8), 785-788, 1987.

Lal, D., and B. Peters, Cosmic ray produced radioactivity on the Earth, Handb. Phys., 46, 551-612, 1967.

Lukasczyk, C. E., ${ }^{36} \mathrm{Cl}$ im Grönlandeis, Ph.D. thesis, Eidg. Tech. Hochsch., Zurich, Switzerland, 1994.

McHargue, L. R., P. E. Damon, and D. J. Donahue, Enhanced cosmicray production of ${ }^{10} \mathrm{Be}$ coincident with the Mono Lake and Laschamp geomagnetic excursions, Geophys. Res. Lett., 22(5), 659-662, 1995.

Raisbeck, G. M., F. Yiou, D. Bourles, C. Lorius, J. Jouzel, and N. I. Barkov, Evidence for two intervals of enhanced ${ }^{10} \mathrm{Be}$ deposition in Antarctic ice during the last glacial period, Nature, 326, 273-277, 1987.

Raisbeck, G. M., F. Yiou, J. Jouzel, J. R. Petit, N. I. Barkov, and E. Bard, ${ }^{10} \mathrm{Be}$ deposition at Vostok, Antarctica, during the last 50,000 years and its relationship to possible cosmogenic production variations during this period, in The Last Deglaciation: Absolute and Radiocarbon Chronologies, edited by E. Bard and W. S. Broecker, pp. 127-139, Springer-Verlag, New York, 1992.

Sharma, P., P. W. Kubik, U. Fehn, H. E. Gove, K. Nishiizumi, and D. Elmore, Development of ${ }^{36} \mathrm{Cl}$ standards for AMS, in 5 International Conference on AMS, pp. 410-415, North-Holland, New York, 1990.

Suter, M., J. Beer, G. Bonani, H. J. Hofmann, D. Michel, H. Oeschger, H. A. Synal, and W. Wölfli, ${ }^{36} \mathrm{Cl}$ studies at the ETH/SIN-AMS facility, Nucl. Instrum. Methods Phys. Res. Sect. B., 29, 211-215, 1987. Synal, H. A., J. Beer, G. Bonani, M. Suter, and W. Wölffi, Atmospheric transport of bomb-produced ${ }^{36} \mathrm{Cl}, \mathrm{Nucl}$. Instrum. Methods Phys. Res. Sect. B., 52, 483-488, 1990

Synal, H. A., J. Beer, G. Bonani, C. Lukasczyk, and M. Suter, ${ }^{36} \mathrm{Cl}$ measurements at the Zürich AMS facility, Nucl. Instrum. Methods Phys. Res., Sect. B, 92, 79-84, 1994.

Taylor, K. C., C. U. Hammer, R. B. Alley, H. B. Clausen, D. DahlJensen, A. J. Gow, N. S. Gundestrup, J. Kipfstuhl, J. C. Moore, and E. D. Waddington, Electrical conductivity measurements from the GISP2 and GRIP Greenland ice cores, Nature, 366, 549-552, 1993.

Yiou, F., et al., Beryllium 10 in the Greenland Ice Core Project ice core at Summit, Greenland, J. Geophys. Res., this issue.

S. Baumgartner and J. Beer (corresponding author), Environmental Physics, Swiss Federal Institute for Environmental Science and Technology, CH-8600 Dübendorf, Switzerland. (e-maili beer@eawag.ch)

B. Dittrich-Hannen and M. Suter, Institute for Particle Physics, Eidgenössische Technische Hochschule Hönggerberg, $\mathrm{CH}-8093 \mathrm{Zu}-$ rich, Switzerland.

C. Hammer and S. Johnsen, Department of Geophysics, University of Copenhagen, DK-2100 Copenhagen, Denmark.

P. W. Kubik and H.-A. Synal, Paul Scherrer Institute, c/o Eidgenössische Technische Hochschule Hönggerberg, CH-8093, Zurich, Switzerland.

(Received January 25, 1996; revised August 8, 1996; accepted January 16, 1997.) 